\title{
Prevalence of Oral Mucosal Lesion in peri-urban area of Lucknow city (Uttar Pradesh)
}

\begin{abstract}
Introduction: The oral mucosa performs essential protective functions that affect the general health of the patient. Oral lesions can cause discomfort or pain that interferes with mastication, swallowing, and speech.

Aim: The aim of this study is to assess the prevalence of oral mucosal lesions in periurban area in the city of Lucknow aged 15 years and above.

Settings and Design: Amultistage random sampling was done for identifying the study sample.

Materials \& Methods: In the first stage. all peri-urban areas of Lucknow city was grouped into four geographical zones. Second stage consisted of random selection of 20 peri-urban areas by lottery method ( 5 from each zone). In third stage there was selection of individuals using simple random method. A total of 45 individuals was selected. Thus a total 900 individuals was selected (i.e. 225 from each zone).

Results: The prevalence of oral mucosal lesion in the present study was found to be $11.8 \%$. The percentage of patients suffering from leukoplakia, oral submucous fibrosis and lichen planus was $51.9 \%, 20.8 \%$ \& $11.3 \%$ respectively. Conclusion: This survey high-lighted the rampant misuse of variety of harmful substances as well as the high prevalence of oral lesions in the community.
\end{abstract}

Keywords: Oral Mucosal Lesions, tobacco, leukoplakia, prevalence.

\section{Introduction:}

Oral health is important to the quality of life of individuals.[1] Oral cavity is called the " physician's mirror" which reflects various systemic conditions.[2] The diagnosis of oral mucosal lesions/conditions is an essential aspect of dental practice. 3 Many lesions/conditions which are habit related or not might undergo malignant changes.[4] It ranks number one among men and three among women in India.[5]

Oral lesions develop as a result of reduced immunologic reactivity, age specific involution and atrophy of oral tissues.[6] The lesions/conditions present a significant health problem.[7] Many patients are severe at diagnosis and incur significant morbidity and mortality.[8] The aim of this study was to assess the prevalence of oral mucosal lesions in periurban area in the city of Lucknow aged 15 years and above.

\begin{tabular}{|l|c|}
\hline \multicolumn{3}{|c|}{ Access this article online } \\
\hline \multirow{2}{*}{$\begin{array}{l}\text { Website: } \\
\text { www.ujds.in }\end{array}$} & Quick Response Code \\
\hline $\begin{array}{l}\text { DOI: } \\
\text { https://doi.org/10.21276/ujds.2020.6.3.12 }\end{array}$ & \\
\hline
\end{tabular}

\section{Materials and Methods:}

The present study was done to assess the prevalence of oral mucosal lesions in peri-urban area of Lucknow city. The list of peri-urban area was taken from the Lucknow Municipal Corporation.

\author{
${ }^{1}$ SINGH, P., ${ }^{2}$ MALHOTRA, S., ${ }^{3}$ AGARWAL, N., \\ ${ }^{4}$ MISHRA, G., ${ }^{5}$ DUBEY, $H$. \\ ${ }_{1,2,3}$ Department of Public Health Dentistry \\ Saraswati Dental College, Lucknow \\ ${ }^{4}$ Department of Oral Medicine and Radiology \\ Career Post Graduate Institute of Dental Sciences \\ ${ }^{5}$ Department of Periodontics Saraswati Dental College \& \\ Hospital, Lucknow
}

Address for Corresponding : Dr. Pallavi Singh Adress: Q-501, Clebrity Meadows, Sushant Golf City, Ansal Api, Lucknow, U.P. 226002

Email-id: pallavirolisingh@gmail.com

Received : 27 Sep.2020, Published : 31 Dec. 2020 
A multistage random sampling was done to identify the study sample. In the first stage of sampling, all the peri-urban areas of Lucknow city was grouped into four geographical zones (North-East, North- West, South-East, South-West). Second stage consisted of random selection of 20 peri-urban areas by lottery method ( 5 from each zone). In third stage there was selection of individuals using simple random method. A total of 45 individuals was selected and interviewed with the help of pretested proforma from each area. Thus a total 900 individuals was selected (i.e. 225 from each zone). The study was conducted among the participants of 15 years and above according to WHO criteria.

Subjects from age 15 years and above, willing to participate and residing in peri-urban areas of Lucknow city were included. Subjects with any systemic or infectious diseases \& younger than fifteen (15) years were excluded.

Ethical clearance was obtained from ethical committee. Oral consent was obtained from each participant prior to the study. Prior to data collection, to maintain consistency of the examination the examiner was trained. The examination was carried out by the principal examiner herself. Training for the diagnosis of oral mucosal lesion was done on 10 adult subjects with wide range of severity. A pilot study was conducted on 50 subjects (15 years and above) one month before the main survey with the aid of predesigned proforma. The sample size was calculated for the study based on prevalence acquired from the pilot survey. The prevalence was 25\%.9 Data was collected by using a pre-tested proforma. The proforma was prepared with the help of World Health Organization's Guide to Epidemiology and Diagnosis of Oral Mucosal diseases.10 A proforma as per WHO criteria 1980 was designed for the collection of all the information needed for planning oral care services. The form included four parts- identification section where personal and demographic information was coded, a section for the recording of habits, a section for recording the nature and location of lesions in the mouth and a section where various information on treatment provided and needed was collected.

Type III clinical examination was carried out by the investigator herself. Examination was carried out in the village. The place which was allotted for examination was clean and noise free. Infection control was carried out at the site of examination by universally accepted method of precautions. Adequate numbers of instruments were carried out to the site of examination, so as to avoid disturbance.

\section{Results:}

In present study more than half $(68.7 \%)$ of the subjects were males. About one third of the subjects were between 31-40 years $(36 \%)$ followed by $20-30(20.8 \%), 41-50$ (19.8\%), 51$60(10 \%),<20(9.4 \%)$ and $>60(4 \%)$ years. The percentage clerical subjects was $59.7 \%$ and unemployed were $40.3 \%$. Any tobacco habit was found among $25.3 \%$ of the subjects. (Fig.1)

The regular cigarette smoking habit was seen among 3\% of the subjects. While, regular cigar smoking was found among only $1.1 \%$ of the subjects. The percentage of other type of smoking habit rare. The regular areca nut lime and leaf was taken by $4.4 \%$ subjects and tobacco chewing was found among $10.4 \%$ subjects.

The toothbrush and tooth paste was used by $57.1 \%$ of the subjects. However, $17.1 \%$ used toothbrush and tooth powder and $13.6 \%$ used Datun. The percentage of other material used was less than $10 \%$. (Fig 2)

Leukoplakia (51.9\%) was the commonest lesion observed followed by OSMF (20.8\%) and Lichen planus (11.3\%). The percentage of other lesions was less than $10 \%$. (Fig 3)

The prevalence of OSMF was $9.6 \%$ among those who had any type of tobacco habit. (Fig 4) The prevalence of OSMF was higher among males $(3.1 \%)$ than females $(1.1 \%)$ and this was 2.89 times insignificantly higher among males compared with females $(R R=2.89,95 \% C I=0.86-9.68, p=0.07)$. Also higher among those who used Gul manjan (12.2\%) than no brushing $(5.6 \%)$.

Overall, the prevalence of Leukoplakia was $6.1 \%$. The prevalence of Leukoplakia was higher among the subjects of age group 51-60 (15.6\%) years than 41-50 (10.7\%), >60 $(5.6 \%), 31-40(4.6 \%)$ and $20-30(2.7 \%)$ years and this association was statistically significant $(\mathrm{p}=0.0001)$. The prevalence of Leukoplakia was significantly higher among male $(7.6 \%)$ subjects compared with females $(2.8 \%)$ and this was 2.68 times higher among males than females $(\mathrm{RR}=2.68$, $95 \% \mathrm{CI}=1.28-5.59, \mathrm{p}=0.006)$. The prevalence of Leukoplakia was higher among those who used Gul manjan (22\%) than figure (10\%), Datun (7.4\%), no brushing (5.6\%), Toothbrush and tooth powder $(5.2 \%)$ and Toothbrush and tooth paste $(3.5 \%)$ and the association was statistically significant $(\mathrm{p}=0.0001)$. (Fig 5) 
The prevalence of Leukoplakia was insignificantly lower among cigarette smokers (3\%) than non-smokers $(6.2 \%)$ and this was $52 \%$ lower among cigarette smokers than nonsmokers $(\mathrm{RR}=0.48,95 \% \mathrm{CI}=0.06-3.41, \mathrm{p}=0.45)$. However, the prevalence of Leukoplakia was higher among any type of smokers (20.5\%) than non-smokers.

Overall, the prevalence of any lesion was found to be $11.8 \%$. The prevalence of any lesion was higher among the subjects of age group 51-60 (33.3\%) years than 41-50 (18\%), >60 (13.9\%), 31-40 (9.9\%) and 20-30 (3.7\%) years. The prevalence of any lesion was higher among cigarette smokers (18.2\%) than non-smokers (11.5\%), however, the difference was statistically not significant $(\mathrm{p}>0.05)$. A significant $(\mathrm{p}=0.0001)$ association was found between prevalence of any lesion and any type of smoking. A significant $(\mathrm{p}=0.001)$ association was observed between prevalence of any lesion and smokeless tobacco habit (Table-1).

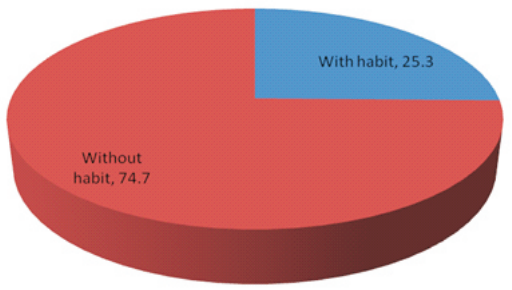

Fig.1: Distribution of study subjects according to tobacco habit

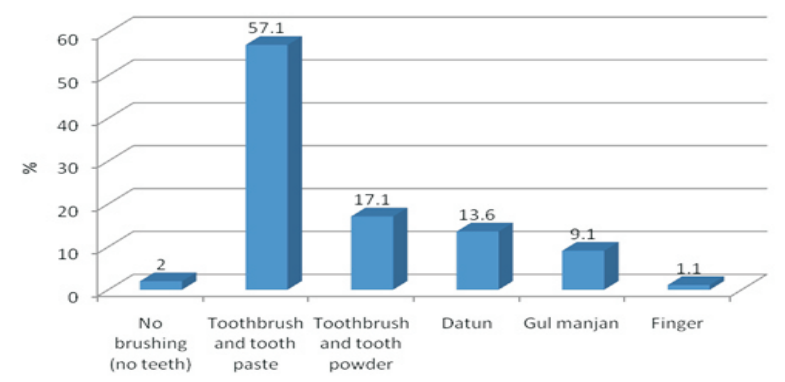

Fig.2: Distribution of the subjects according to Oral hygiene practices

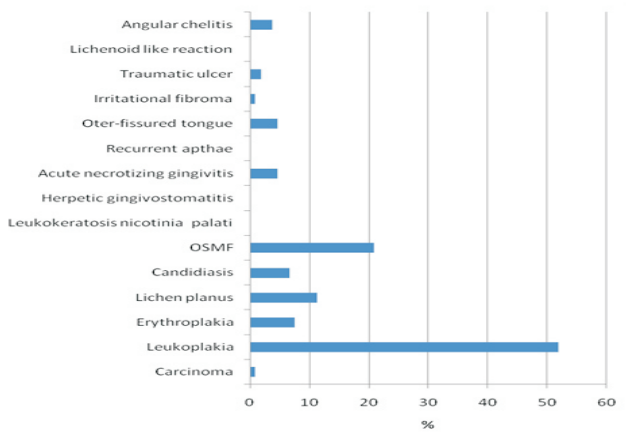

Fig.3: Distribution of the subjects according to type of lesion

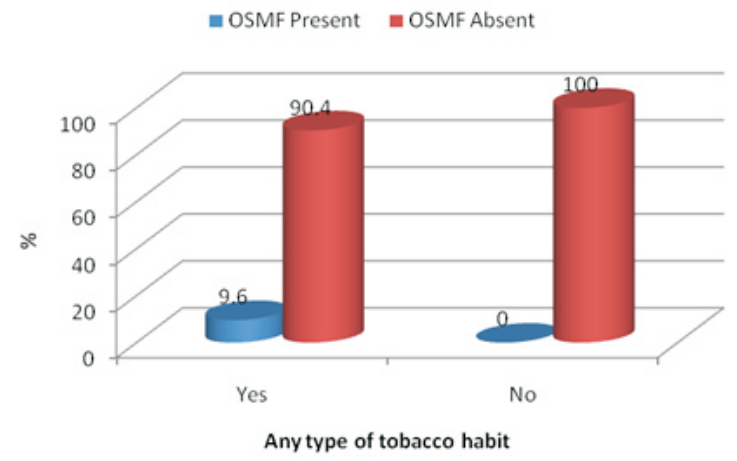

Fig.4: Association of OSMF with any type of tobacco habit

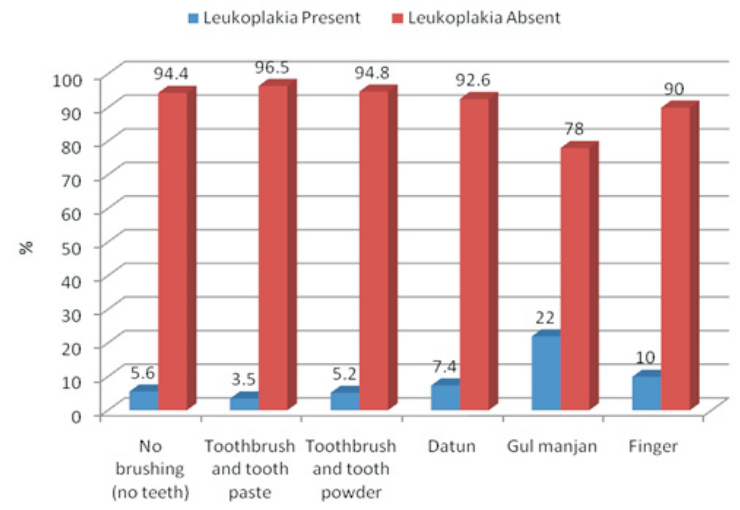

Fig.5: Association of Leukoplakia with oral hygiene practices of the subjects

\begin{tabular}{|c|c|c|c|c|c|c|}
\hline \multirow{3}{*}{$\begin{array}{l}\text { Smokeless tobacco } \\
\text { habit }\end{array}$} & \multirow{3}{*}{$\begin{array}{c}\text { No. of } \\
\text { subjects }\end{array}$} & \multicolumn{4}{|c|}{ Any lesion } & \multirow{3}{*}{$\begin{array}{c}\text { RR }(95 \% \mathrm{CI}), \mathrm{p}- \\
\text { value }\end{array}$} \\
\hline & & \multicolumn{2}{|c|}{ Present } & \multicolumn{2}{|c|}{ Absent } & \\
\hline & & No. & $\%$ & No. & $\%$ & \\
\hline \multicolumn{7}{|l|}{$\begin{array}{l}\text { Areca nut lime } \\
\text { and leaf }\end{array}$} \\
\hline Yes & 51 & 24 & 47.1 & 27 & 52.9 & \multirow{2}{*}{$\begin{array}{c}4.87(3.41-6.95) \\
0.001^{*}\end{array}$} \\
\hline No & 849 & 82 & 9.7 & 767 & 90.3 & \\
\hline \multicolumn{7}{|l|}{ Tobacco chewing } \\
\hline Yes & 101 & 65 & 64.4 & 36 & 35.6 & \multirow{2}{*}{$\begin{array}{c}12.54(9.00-17.47) \\
0.001 *\end{array}$} \\
\hline No & 799 & 41 & 5.1 & 758 & 94.9 & \\
\hline \multicolumn{7}{|l|}{$\begin{array}{l}\text { Any tobacco } \\
\text { chewing }\end{array}$} \\
\hline Yes & 140 & 77 & 55.0 & 63 & 45.0 & \multirow{2}{*}{$\begin{array}{c}14.41(9.78-21.22) \\
0.001^{*} \\
\end{array}$} \\
\hline No & 760 & 29 & 3.8 & 731 & 96.2 & \\
\hline
\end{tabular}

Table-1: Association of any lesion with type of smokeless tobacco habit

RR-Relative risk, CI-Confidence Interval, *Significant

\section{Discussion:}

In the present study more than half $68.7 \%$ of the subjects were male. About one-third of the subjects were between 31-40 years $(36 \%)$. About twenty five point three percent of the subjects were reported with the habit of consuming tobacco. Of which $14.8 \%$ of the subjects were reported with the habit of chewing tobacco that is smokeless tobacco consumption. $4.1 \%$ of the subjects were found with the habit of smoking tobacco. $3.2 \%$ of the subjects were found with the habit of 
both that is chewing tobacco and smoking tobacco. $17.1 \%$ of the subjects used toothbrush and toothpowder for their oral hygiene maintenance. $13.6 \%$ of the subjects were in a habit of using datun.

The higher prevalence of oral mucosal lesions (23.6\%) observed among males in the present study, might be due to an associated higher prevalence of oral habits. Similar higher prevalence of oral mucosal lesions among males was shown by Bouquot JE, Darwazeh AMG and Pillai K,11 and Lin HC et al 2001,[12] Axell Tet al.]13]

The present study showed higher prevalence of oral mucosal lesion among clerical and unemployed subjects which was $4.3 \%$ which could be probably due to the lesser levels of knowledge regarding oral health and ignorance and was in accordance with the study of Shivakumar GC et al 2010.[6]

The prevalence of oral mucosal lesion in the present study was found to be $11.8 \%$ which was in accordance with the study of Mehrotra R et al 2010 in which the prevalence of clinically significant oral lesions was $8.4 \% 14$ and comparatively lower with the study Saraswathi TR etal 2008 in which the prevalence of oral lesion was $4.1 \%$.[15]

Of the clinically significant lesions, the percentage of patients suffering from leukoplakia, oral submucous fibrosis and lichen planus was $51.9 \%, 20.8 \% \& 11.3 \%$ respectively which was in accordance with the study of Patel P, Patel V 201116 where the percentage of patients suffering from leukoplakia was $40.7 \%$, oral submucous fibrosis was $9.7 \%$ and lichen planus was $2.7 \%$.

Among other lesions, prevalence of erythroplakia was highest $(7.5 \%)$ followed by candidiasis $(6.6 \%)$, acute necrotizing gingivitis $(4.7 \%)$, fissured tongue $(4.7 \%)$ and angular chelitis (3.8\%). The prevalence of oral candidiasis in our population was $6.6 \%$ which is in accordance with the study of Mathew AL et al (2008)17 in which it was found to be 3.07\%.

The oral cavity is one of the most suitable locations for the development of oncologic disease. Most oral cancers, especially palpable squamous cell carcinomas involving the mucosal tissue, are usually evident. In the present study, 1 patient $(0.1 \%)$ was diagnosed as having squamous cell carcinoma which is almost in agreement with the studies reported by Axell T (1990).[18] et al in which it was found to be $0.4 \%$.
It was noted during the study tenure that most of the subjects having oral lesions or conditions were asymptomatic or the patient was not aware of the condition. This emphasizes the importance of a full and a careful examination of the entire oral cavity. In addition, it highlights the necessity for the dentists to be aware of the common oral lesions and conditions.

\section{Conclusion:}

This study presents epidemiological data on oral mucosal lesions. Nearly three-fourths of the patients with a tobacco habit had oral mucosal lesions. This might prove valuable in identifying high-risk populations, planning future oral health studies and implementing preventive programmes. The patients, especially the younger population, have to be counselled on a regular basis in order to bring about long-term results with regard to tobacco cessation.

\section{References}

1. Cebeci ARI, Gulsahi A, Kamburoglu K, Orhan BK, Oztas B- Prevalence and distribution of oral mucosal lesions in an adult Turkish population.- Med Oral Patol Oral Cir Bucal, 2009 Jun 1;14 (6):e272-7.

2. Manjunath C, Veeresha KL- Prevalence of oral mucosal lesions among outpatients attending Government Dental College, Bangalore- Journal of the Indian Association of Public Health Dentistry Vol: 2011 ISSUE:17 SUPPL.1,213-16.

3. Jahanbani J, Morse DE, Alinejad H. Prevalence of oral lesions and normal variants of the oral mucosa in 12 to 15-year-old students in Tehran, Iran. Arch Iran Med.2012;15(3):142-145.

4. Castellanos JL, Guzman LD. Lesions of the oral mucosa: An epidemiological study of 23785 Mexican patients. Oral Surg Oral Med Oral Pathol Oral Radiol Endod 2008;105:79-85.

5. Nagpal R, Saha S, Sahana S- Prevalence of oral mucosal lesions in tobacco and alcohol using population of Lucknow City: A hospital based pilot study- Journal of the Indian Association of Public Health Dentistry Vol: 2008 ISSUE: $12,45-51$.

6. Shivakumar GC, Sahana S, Saha S- Prevalence and site distribution of oral mucosal lesions in patients attending outpatient clinics of Oxford Dental College, BangaloreJournal of the Indian Association of Public Health Dentistry Vol: 2010 ISSUE: 15, 69-73. 
7. Mobeeriek AA, Dosari AM.AL- Prevalence of oral lesions among Saudi dental patients-Ann Saudi Med. 2009 Sept-Oct;29(5): 365-368.

8. Sabrina Daniela da Silva, Alfio Ferlito, Robert P. Takes.Oral oncology: Advances and applications of oral cancer basic research. 47(2011) 783-791.

9. R Mehrotra, Thomas S, Nair P et al- Prevalence of oral soft tissue lesions in Vidisha: BMC Research Notes 2010,3-23.

10. World Health Organization. Guide to Epidemiology and Diagnosis of Oral Mucosal Diseases \& Conditions. Community Dent Oral Epidemiol 1980;8: 1-26.

11. Thavarajah R, Rao A, Raman U et al- Oral lesions of 500 habitual psychoactive substance users in Chennai, India: Archives of Oral Biology (2006)51, 512-519.

12. Lin HC, Corbet EF, Lo EC-Oral mucosal lesions in adult Chinese. J Dent Res. 2001 May;80 (5): 1486-90

13. Ghanaei FM, Joukar F, Rabiei M et al- Prevalence of Oral Mucosal Lesions in an Adult Iranian Population: Iranian Red Crescent Medical Journal. 2013 July; 15(7): 600-604.

14. Mehrotra R, Thomas S, Nair P et al- Prevalence of oral soft tissue lesions in Vidisha: BMC Research Notes 2010, 3:23

15. Saraswathi TR, Ranganathan K, Shanmugam S et alPrevalence of oral lesions in relation to habits: a cross sectional study in South India. Ind J Dent Res, 2008; 17(3): $121-125$.

16. Patel P, Patel V- Oral mucosal lesions among residence of a Town in North Gujarat: National Journal of Medical Research;Vol 1 Issue 1 July - Sept 2011 :3-6.

17. Mathew AL, Pai KM, Sholapurkar AA, Vengal M-The prevalence of oral mucosal lesions in patients visiting a dental school in Southern India, Year-2008 Volume: 19 Issue : 2 Page: $99-103$.

18. Axell T, Zain RB, Siwamogstham P et al: Prevalence of oral soft tissue lesions in out-patients at low Malaysian and Thai dental schools. Community Dent Oral Epidemiol 1990;18: 95-9. 